\title{
The Usability of Electronic Stores based on the Organization of Information and Features
}

\author{
CHAN KAH-SING \\ Singapore Polytechnic
}

\begin{abstract}
This paper describes an investigation on how the perceived usability of electronic stores is affected by the organization of information and features. An experiment was developed to measure the perceived usability of a sample of electronic stores. This allowed for systematic comparison of information items and features between "high usability" and "low usability" stores. Within the sample of electronic stores tested, there were evidences that the perceived usability of an electronic store is affected by its organization of information and features. This suggests that it is timely to eliminate inconsistent store design as a factor contributing to the consumers' negative perception of electronic retailing. This usability testing approach can provide the basis for developing usable electronic store systems.
\end{abstract}

Additional Key Words and Phrases: Consumer Behavior, Electronic Business, Electronic Commerce, Information Management, Internet.

\section{INTRODUCTION}

This paper describes an investigation on how the perceived usability of electronic stores is affected by the organization of information and features. In a study conducted at the Singapore Polytechnic from 2000 to 2001, quantitative indicators of perceived usability were obtained through a usability test exercise. The results were used to relate to the organization of information and features with respect to purchase decision-making.

\section{BACKGROUND}

This study arose from observations that there are many inconsistencies in the organization of information and features in electronic stores. These inconsistencies can cause distractions, confusions, and frustrations among consumers. To many, an electronic store is perceived to be complex, confusing, and do not meet expectations. The outcome is a proliferation of electronic stores of poor usability.

As consumers encounter such inconsistent processes in electronic stores, they need to put in additional efforts to learn and understand them. The learning process is further aggravated when the processes consumers need to go through are significantly different from conventional purchase and decision-making processes that they are used to in the physical marketplace. All these usability issues give the general consumer negative perceptions of electronic retailing. 


\section{USABILITY OF ELECTRONIC STORES}

The usability approach aims to make computer systems easier and more satisfying to use. Shackel (1984) defined usability as:

"the capability (of a system) to be used by humans easily (to a specified level of subjective assessment such as comfort, confidence, and satisfaction) and effectively (to a specified level of performance such as time and errors in carying out operations) by the specified range of users, given specified user support, to fulfill the specified range of tasks, within the specified range of environmental scenarios."

Following the usability approach, an electronic store has to be designed with an understanding of the consumer's task. The tasks that consumers would do on an electronic store are very much related to the purchase decisionmaking process. In many instances, they need to search for information to enable them to decide with a degee of confidence. To a certain extent, the effectiveness of information search is influenced by the organization of information and features. These features collectively form the electronic processes to support the consumer's task.

\section{USABILITY TEST EXERCISE}

\subsection{Usability Test Design}

In order to study the usability of electronic stores, there was a need to systematically measure the perceived usability construct. The approach taken was that along the lines of usability test methods (see for example Nielsen(1993, 165-206), Lindgaard (1994, 248-83), Shneiderman (1998, 12745), and Mayhew (1999, 353-99)). As perceived usability is a construct, it had to be deduced from indirect measurements made on a questionnaire.

Each usability test consisted of a prescribe task to be performed on a particular electronic store for a particular product. Test users were engaged to carry out a task on the selected store. In performing the task, the users were required to carry out product comparisons, search for prices, find out payment options, delivery options and charges, return policies, and warranties. However, they were not required to finalize the purchase or incur any payment as part of the task.

Following that, each test user provided quantitative feedback on a usability task questionnaire. The quantitative feedback was translated into a usability score, and this served as a quantitative indicator of the perceived usability of the store.

\subsection{Usability Task Questionnaire}

For each test conducted, the questionnaire had tocapture quantitative indicators that could be translated to a usability score. The questionnaire had twentyfive variables, as shown in Table I. Each variable consisted of a statement for the test user to respond to a fivepoint Likert scale, ranging from "Strongly Disagree" (1 point) to "Strongly Agree" (5 points).

\subsection{Usability Test Plan}

The test plan was required to secure sufficient data for analysis using the Analysis of Variance (ANOVA) method. In view of variations in carrying out usability tests, a certain level of control had to be imposed to maintain consistency and to reduce the effects of external physical variables that were difficult to control. Each test user was randomly assigned usability tests for different product-store combinations, for example, buying a PC Printer (product) from Gateway.com (store). The exercise involved 334 test users. 
Table I. Usability Task Questionnaire Variables

\begin{tabular}{|c|c|}
\hline No. & Variable Statement \\
\hline 01 & I am familiar with this product (or service). \\
\hline 02 & $\begin{array}{l}\text { I am familiar with shopping for such products (or engaging such services) the } \\
\text { conventional way. }\end{array}$ \\
\hline 03 & I am familiar with the operations of this site. \\
\hline 04 & I managed to complete this task. \\
\hline $05^{*}$ & Generally, I was frustrated while doing this task. \\
\hline 06 & The overall time taken to complete this task was acceptable. \\
\hline 07 & The response (access) time from this site was acceptable. \\
\hline 08 & While doing the task, there were no distracting features. \\
\hline 09 & From one step to another, I always knew what to do next. \\
\hline 10 & $\begin{array}{l}\text { If I were to perform this task againanother time, I would be able to remember the steps I } \\
\text { just did. }\end{array}$ \\
\hline 11 & $\begin{array}{l}\text { I felt that doing this task was compatible with how people would do it conventionally (the } \\
\text { physical way). }\end{array}$ \\
\hline $12 *$ & I had to search for specific information from the site to guide me in carryigout this task. \\
\hline $13^{*}$ & The search for information was very difficult. \\
\hline 14 & I found all the information that I expected to find. \\
\hline 15 & The organization of information on the screen was logical. \\
\hline 16 & The quality of information was excellent. \\
\hline 17 & It was easy to understand the site's directions for this task. \\
\hline 18 & I was comfortable with the navigation process. \\
\hline 19 & This site allowed me to navigate freely. \\
\hline 20 & I felt that the navigation process was very logical. \\
\hline 21 & I liked the general layout of this site. \\
\hline $22 *$ & I made many mistakes while performing this task. \\
\hline $23^{*}$ & The features were much too difficult to learn. \\
\hline 24 & I found doing this task on this site very interesting. \\
\hline 25 & Overall, I found this site very easy to use. \\
\hline
\end{tabular}

Note. These are the variables in the usability taskquestionnaire that a test user filled up to provide quantitative feedback after performing a usability test. Note that the Likertscale response items are not shown above. The variables with numbers marked with an asterisk "*” are statements that were worded in such a way for reverse scoring. 


\subsection{Data Consolidation}

The test users conducted a total of 109 usability tests on 73 different electronic stores, covering 25 different products. This resulted in 3,996 observations. For each productstore combination, the usability score was computed as the mean of the variable scores, with adjustments made to reverse-scored variables. The numerical value of the scores ranged from 1 (lowest usability) to 5 (highest usability).

The data were inspected prior to statisical analysis, in particular, checks on sample sizes, data completeness, and integrity. The data was also used to check the questionnaire for validity and reliability of measurement. Certain observations were disregarded from further analyses to avoid possible bias. All in all, this resulted in the rejection of 478 observations, leaving 3,518 valid observations for further analysis.

\section{ANALYSIS}

\subsection{Relative Usability Scores}

For each product, Analysis of Variance (ANOVA) was used to study the variations of usability scores across different stores. Where significant differences were detected among the means of the treatments, post hoc range tests and pairwise multiple comparisons were used to identify the treatments that accounted for the significant differaces. These tests determined the difference between each pair of means at a significance level of 0.05 . As variances of these samples were not homogeneous, the pairwise multiple comparison test used was the GamesHowell test (SPSS 1999, 257, 269).

To provide for a systematic method of analysis, the evaluation of information items and features was based on relative usability scores. The treatments were ranked by usability scores. Where there were significant differences between these scores, the treatmentsene divided into two categories, namely "high" and "low usability" stores. The largest gap between usability scores was used as the dividing line between these two categories.

In cases where there were no significant differences between the treatments unde investigation, then a mean score was taken from the treatments, and all of them were placed into either of the two usability groups. Generally, treatments with a mean score of higher than the mid point score of 3.000 were grouped under "high usability."

The introduction of relative usability scores was appropriate because comparisons could be made within groups, and across groups, instead of having to compare individual stores. In effect, this was to cater for an inspection of distinctive information item and features that were present in "high usability" stores.

\subsection{Information Items and Features}

To study the organization of information and features for each store, the information items and features present in the home page, common navigation bar, site map, help page, search mechanism, product page and shopping cart were documented and tabulated.

Table II lists selected information items and features that had very low adoption rates among the stores. These items do play an important part in consumer decsion-making, regardless of the product. These findings were not surprising but was rather disturbing in the sense that some of these stores, especially the "low usability" ones, had missed out on providing information items and features that should be mandatory for any purchase process.

The tabulation of information items and features facilitated comparisons between "high" and "low usability" stores, in particular, to identify those that contributed to "high usability." Two approaches were used for comparion: using descriptive evidences, and using inferential evidences. 
Table II. Selected Items and Features with Low Adoption Rates ${ }^{1}$

\begin{tabular}{|c|c|c|}
\hline $\begin{array}{c}\text { Store } \\
\text { Component }\end{array}$ & Item/Feature & $\begin{array}{c}\text { Proportion of stores } \\
\text { containing this Item/Feature } \\
(\mathrm{n}=71)\end{array}$ \\
\hline Home Pages & $\begin{array}{l}\text { Site Navigation } \\
\text { Advance Search Mechanism } \\
\text { Site Map } \\
\text { Purchase Features } \\
\text { Delivery Information } \\
\text { Return Policy } \\
\text { Customer Assistance } \\
\text { Search Tips } \\
\text { Safe Shopping Guarantee } \\
\text { Learn about Product }\end{array}$ & $\begin{array}{r}33 \% \\
24 \% \\
\\
13 \% \\
20 \% \\
\\
3 \% \\
20 \% \\
14 \%\end{array}$ \\
\hline $\begin{array}{l}\text { Common } \\
\text { Navigation Bars }\end{array}$ & \begin{tabular}{|l|} 
Site Navigation \\
Basic Search Mechanism \\
Advance Search Mechanism \\
Site Map \\
Product Categories
\end{tabular} & $\begin{array}{l}58 \% \\
21 \% \\
23 \% \\
30 \%\end{array}$ \\
\hline Help Pages & $\begin{array}{l}\text { Purchase Information } \\
\text { Ordering } \\
\text { Payment } \\
\text { Tax } \\
\text { Delivery } \\
\text { Returns }\end{array}$ & $\begin{array}{l}55 \% \\
48 \% \\
20 \% \\
72 \% \\
56 \%\end{array}$ \\
\hline $\begin{array}{l}\text { Product Details } \\
\text { Pages }\end{array}$ & $\begin{array}{l}\text { Product-Independent Features } \\
\text { Product Availability } \\
\text { Tax } \\
\text { Delivery Information } \\
\text { Select Quantity } \\
\text { Product-Dependent Features } \\
\text { "Compare" Feature } \\
\text { Warranty } \\
\text { Product Options }\end{array}$ & $\begin{array}{r}20 \% \\
3 \% \\
20 \% \\
34 \% \\
3 \% \\
10 \% \\
27 \%\end{array}$ \\
\hline Shopping Carts & $\begin{array}{l}\text { Product Information } \\
\text { Product Availability } \\
\text { Tax } \\
\text { Delivery } \\
\text { Purchase Features } \\
\text { "Save Shopping Cart" }\end{array}$ & $\begin{array}{r}15 \% \\
10 \% \\
30 \% \\
1 \%\end{array}$ \\
\hline
\end{tabular}

Note

$\frac{N}{1}$ Low adoption rate here is taken to be less than 60 percent.

\subsection{Comparison using Descriptive Evidences}

The usability test exercise had provided lists of "high usability" and "low usability" stores. For each item or feature, the proportion of "high usability" sores adopting it was first determined. This was then repeated for the "low usability stores." The difference between these two proportions was then calculated. A high difference in proportion indicates that the item or feature was implemented more in "high usability" stores than in "low usability" ones. 


\subsection{Comparison using Inferential Evidences}

This approach used multiple regression analyses to identify items and features that significantly influenced usability scores. The stepwise version of multiple egression was used to determine a combination of items and features (as independent variables) that contributed most significantly to usability scores (as dependent variables). As this multiple regression model involved qualitative variables, binary dichotomous (zero-one) indicators were used as dummy independent variables to represent the information items. The model with the highest coefficient of determination (R2) gave the information items that contributed most significantly to the usability scores.

\section{RESULTS}

Within the sample of electronic stores tested, statistical analyses revealed that there were significant differences in usability scores between stores, and that the usability of stores was dependent on the product. More so, the results indicatedthat there were inconsistencies in the implementation of the major items and features.

Tables III and IV present a sample of the more significant results from the experiment. Table III summarizes items and features that were present more in "high usability" stores; and at the other extreme, Table IV provides those that were present more in "low usability" stores. Between these two tables, the results in Table III were more significant as the magnitudes of the differences in proportions were larger.

\section{DISCUSSIONS}

\subsection{Limitations of Results}

It was not practical to collect and analyze a large number of variables, so the questionnaire had to limit to key variables that were deemed to have significant influence on perceived usability. Therefore, the process ofdeveloping the questionnaire balanced the needs of validity, reliability and practicality, to allow for quick and easy completion. With regards to the experiment, there was a practical limitation on the number of products and electronic stores covered inview of constraints of time, practicalities and limitations of computer laboratory testing, and the voluntary involvement of many test users.

\subsection{General Observations}

The results indicate that the perceived usability of an electronic store is affected byits organization of information and features. It also suggests that electronic stores do not seem to subscribe to an underlying list of mandatory information items and features. On the contrary, physical stores do follow certain standard practices that arecontinuously being investigated under studies in retail management. This discussion highlights three aspects that are important to consumer decisionmaking: product categorization, product specifications, and supporting information and services. 
Table III. Items and Features present in more "High Usability" Stores

\begin{tabular}{|c|c|c|c|c|}
\hline \multirow{3}{*}{$\frac{\text { Store Component }}{\text { Item/Feature }}$} & \multicolumn{3}{|c|}{ Descriptive Evidences } & \multirow{3}{*}{$\begin{array}{l}\text { Inferential } \\
\text { Evidences }^{3}\end{array}$} \\
\hline & $\begin{array}{l}\text { Proportion of } \\
\text { "high usability" } \\
\text { stores containing } \\
\text { this item/feature } \\
\quad(\mathrm{n}=71)\end{array}$ & $\begin{array}{l}\text { Proportion of } \\
\text { "low usability" } \\
\text { stores containing } \\
\text { this item/feature } \\
(\mathrm{n}=55)\end{array}$ & $\begin{array}{l}\text { Difference in } \\
\text { Proportions }^{2}\end{array}$ & \\
\hline & $(1)$ & (2) & $(1)-(2)$ & \\
\hline $\begin{array}{l}\text { Home Pages } \\
\text { Basic Search Mechanism } \\
\text { Links to: }\end{array}$ & $85 \%$ & $63 \%$ & $22 \%$ & Yes \\
\hline $\begin{array}{l}\text { ??Shopping Cart } \\
\text { ??Help/FAQ } \\
\text { ??Privacy/Security Statement } \\
\text { ??Learn about Product }\end{array}$ & $\begin{array}{l}87 \% \\
84 \% \\
76 \% \\
18 \%\end{array}$ & $\begin{array}{r}61 \% \\
68 \% \\
56 \% \\
2 \%\end{array}$ & $\begin{array}{l}26 \% \\
15 \% \\
20 \% \\
16 \%\end{array}$ & $\begin{array}{l}\text { Yes } \\
\text { Yes }\end{array}$ \\
\hline $\begin{array}{l}\text { Common Navigation Bars } \\
\text { Links to: } \\
\text { ??Home } \\
\text { ??Basic Search Mechanism } \\
\text { ??Shopping Cart } \\
\text { ??Privacy/Security Statement } \\
\text { ??Customer Account }\end{array}$ & $\begin{array}{r}100 \% \\
84 \% \\
84 \% \\
65 \% \\
38 \% \\
\end{array}$ & $\begin{array}{l}90 \% \\
59 \% \\
59 \% \\
39 \% \\
22 \%\end{array}$ & $\begin{array}{l}10 \% \\
25 \% \\
25 \% \\
26 \% \\
16 \% \\
\end{array}$ & Yes \\
\hline $\begin{array}{l}\text { Help Pages } \\
\text { Search Tips } \\
\text { Tax }\end{array}$ & $\begin{array}{l}35 \% \\
36 \%\end{array}$ & $\begin{array}{l}15 \% \\
20 \%\end{array}$ & $\begin{array}{l}20 \% \\
17 \%\end{array}$ & $\begin{array}{l}\text { Yes } \\
\text { Yes }\end{array}$ \\
\hline $\begin{array}{l}\text { Product Pages } \\
\text { "Buy" button } \\
\text { Product Specifications } \\
\text { Product Reviews }\end{array}$ & $\begin{array}{r}100 \% \\
76 \% \\
22 \% \\
\end{array}$ & $\begin{array}{r}90 \% \\
54 \% \\
5 \% \\
\end{array}$ & $\begin{array}{l}10 \% \\
23 \% \\
17 \%\end{array}$ & $\begin{array}{l}\text { Yes } \\
\text { Yes } \\
\text { Yes }\end{array}$ \\
\hline $\begin{array}{l}\frac{\text { Notes }}{1} \text { The method of comparing } \\
\text { usability" stores was to co } \\
\text { A high difference in propo } \\
\text { usability" stores that in " } 1 \\
\text { are listed. } \\
\text { Items or features marked " } \\
\text { inferential evidence. }\end{array}$ & $\begin{array}{l}\text { the adoption of iter } \\
\text { mpute the differen } \\
\text { rtion indicates that } \\
\text { ow usability" store } \\
\text { "Yes" indicate that }\end{array}$ & $\begin{array}{l}\text { ns and features bety } \\
\text { ce in proportion im } \\
\text { the feature was im } \\
\text { Differences great } \\
\text { the descriptive evi }\end{array}$ & $\begin{array}{l}\text { en "high"and " } \\
\text { lemented. } \\
\text { emented more } \\
\text { r than or equl to } \\
\text { ence is supporte }\end{array}$ & $\begin{array}{l}\text { ow } \\
\text { " high } \\
10 \text { percent } \\
\text { by }\end{array}$ \\
\hline
\end{tabular}


Table IV. Items and Features present in more "Low Usability" Stores

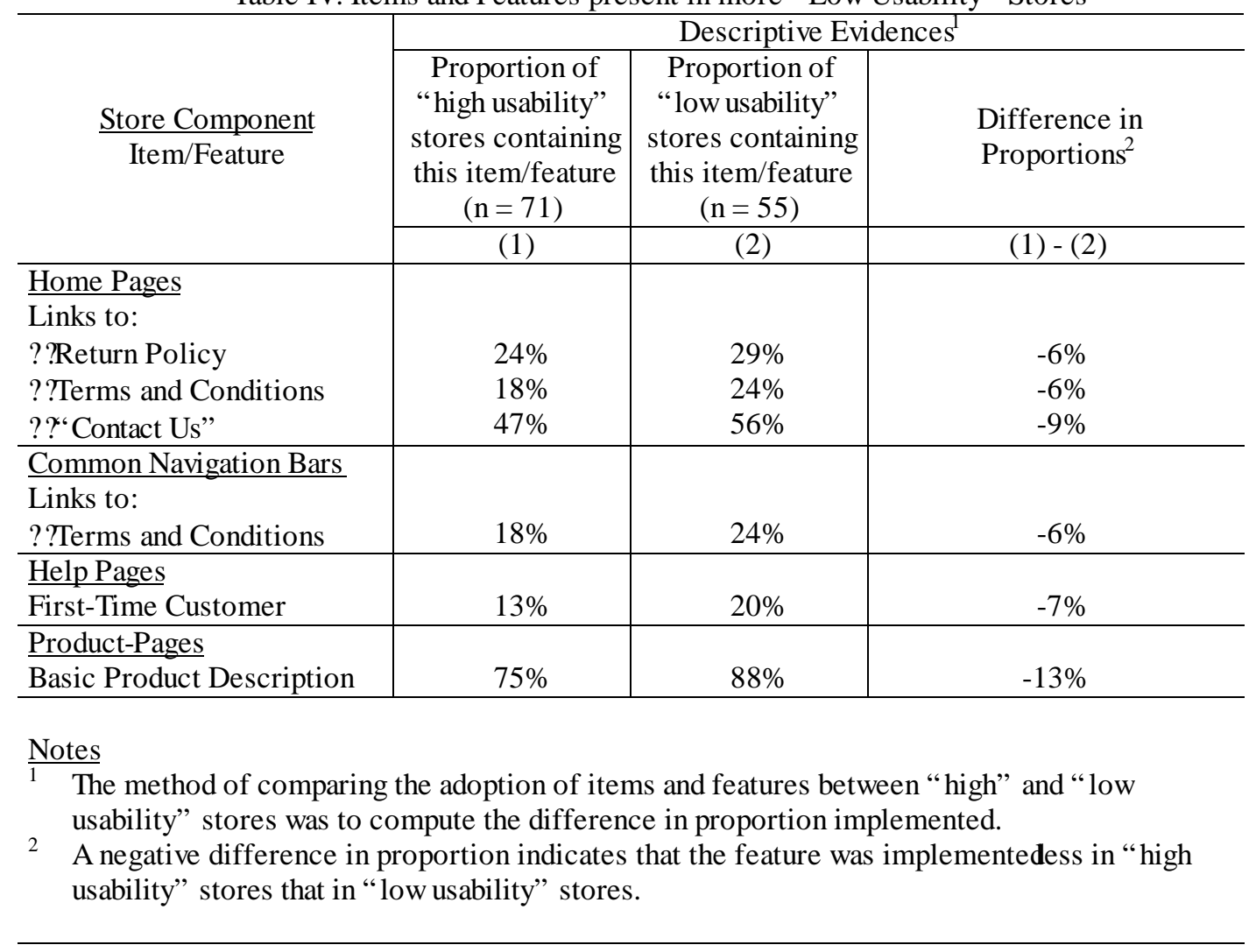

\subsection{Product Categories}

Only 56 percent of the stores evaluated displayed their product categories on the home page, and 30 percent had them on the common navigation bar. Of the "high usability" stores, only 62 percent had product categories on the home page, and 27 percent had them on the common navigation bar. Despite the low adoption rate, this was distinct enough when compared to the adoption rate of "low usability" stores, which was 49 percent and 24 percent respectively.

A product categorization system that is logical and consistent with the consumers' product knowledge would facilitate efficient decisionmaking. This implies that categorization would help consumers form an awareness set and further narrow down their choices to an evoked set before evaluating the alternatives. In determining a suitable categorization system, the electronic store will have a distinct advantage over its physical counterpart. Physical retailers do not havemuch flexibility in physical store arrangements. Therefore, they have to decide on basically one method of organizing products and adopt it.

\subsection{Product Specifications}

Only 61 percent of stores evaluated and 76 percent of "high usability" stores provideфroduct specifications on the product details page. The presentation of items in this page is particularly important as it helps consumers understand the product and make a decision based on it.

Consumers have so many choices and so much conflicting dataon each choice that they may tend to discount such information. If too detailed specifications were provided, this could confuse consumers and cause information overload. Therefore, the organization of information items is an important consideration as it could influence the consumers in setting the appropriate evaluation criteria. 


\subsection{Supporting Information and Services}

Among the stores investigated, it was found that there were significant variations in the implementation of information items on the hep page. The common features were information on delivery (found in 72 percent of the stores), privacy/security (61 percent), and return policies (56 percent).

Few physical products as they come off the assembly line, match the variety of needs individuals have. In this case, supporting information and services are included in connection with the sale of physical products in order to provide value to consumers. The important ones are delivery, warranty, repairs, and return policies. Other services that inflence the consumer's decision to purchase include payment methods, phone and fax ordering, gift certificates, gift cards and wrapping, providing consumer information, leasing, and handling of complaints. Such services can be the deciding factor in a purchas.

The help page is a common feature of application systems. This page was supposed to be a source of information for a user who encounters problems with the system, however, many electronic stores used this feature to provide general information and diretions for carrying out tasks. In effect, the help page is presumably a mandatory item on many stores. However, its contents remain an issue due to inconsistent implementation.

\section{IMPLICATIONS OF THE RESULTS}

The results of this study have broad implications on electronic retailing. As it is now, many electronic stores today have not adopted common designs or standardized features. This is unlike their physical counterparts, where standard retail management concepts have been established. In the physical marketplace, such practices are not really considered as factors for competitive advantage as many retailers practiced them widely. However, this does not seem to be the same for the electronic marketplace, and this goes to show the immaturity of developmentshere. In many cases, concepts that have been developed for the physical marketplace are not practiced in the electronic marketplace.

The results suggest that it is timely to eliminate inconsistent store design as a factor contributing to the consumers' negative perception of electronic retailing. The organization of information and features in an electronic store should not be an issue. Instead, businesses should focus on competing based on better products and services as that practiced in the physical marketplace.

\section{ACKNOWLEDGMENTS}

I wish to express my appreciation to Prof. dr. Dragan A. Nikolik of the Maastricht School of Management (The Netherlands) for his guidance and support in this project; and to the 334 students of the Singapore Polytechnic for carying out the usability tests.

\section{REFERENCES}

LINDGAARD, G. 1994. Usability Testing and System Evaluation: A Guide for Designing Useful Computer Systems. Chapman \& Hall, London, UK.

MAYHEW, D.J. 1999. The Usability Engineering Lifecycle: A Practitioner's Handbook for User Interface Design. Morgan Kaufmann, San Francisco, CA.

NIELSEN, J. 1993. Usability Engineering. AP Professional, Boston, MA

SHACKEL, B. 1984. The concept of usability. In Visual Display Terminals: Usability Issues and Health Concerns, J. BENNE TT, D. CASE, J. SANDELIN, and M. SMITH, Eds. Prentice Hall, Englewood Cliffs, NJ, 45-87.

SHNEIDERMAN, B. 1998. Designing the User Interface: Strategies for Effective Human-Computer Interaction, 3rd ed. Addison-Wesley, Reading, MA

SPSS. 1999. SPSS ${ }^{\circledast}$ Base 9.0 User's Guide. SPSS Inc., Chicago, IL. 